\title{
IMPACT OF FEEDSTOCK PROPERTIES ON THE DEACTIVATION OF A VACUUM GASOIL HYDROCRACKING CATALYST
}

\author{
July C. VIVAS-BÁEZ ${ }^{a, b}$, Gerhard PIRNGRUBER ${ }^{a}$, Alberto SERVIA ${ }^{a}$, Anne-Claire DUBREUIL ${ }^{a}$, David J. \\ PÉREZ-MARTÍNEZ \\ a IFP Energies nouvelles, Rond-point de l'échangeur de Solaize, France, 69360. \\ b Centro de innovación y tecnología ICP, ECOPETROL S.A., Km 7 vía Piedecuesta, Piedecuesta, Colombia, 681011. \\ Corresponding Author: Gerhard PIRNGRUBER (mailto:gerhard.pirngruber@ifpen.fr)
}

\section{Supporting Information}

Figure $S$ 1. DBE versus number of carbon plots for feed $A$ and feed $B$ from FT-ICR/MS, ESI (+) and ESI (-) modes focusing on the $\mathrm{N} 1[\mathrm{H}]$ class

Figure S 2. Exponential and hyperbolic decay models for test with feed A during $\mathbf{3 0}$ days Figure S 3. Exponential and hyperbolic decay models for test with feed B during 30 days

Figure S 4. Characterization of spent catalysts: loss of surface area (S) as function of carbon deposition

Figure S 5. Characterization of spent catalysts: loss of pore volume (V) as function of carbon deposition.

\section{S 6. Hydrogen consumption}

S 7. Transmission electron microscopy (TEM) results 
Figure S 6. DBE versus number of carbon plots for feed A and feed B from FT-ICR/MS, ESI (+) and ESI (-) modes focusing on the $\mathrm{N} 1[\mathrm{H}]$ class.
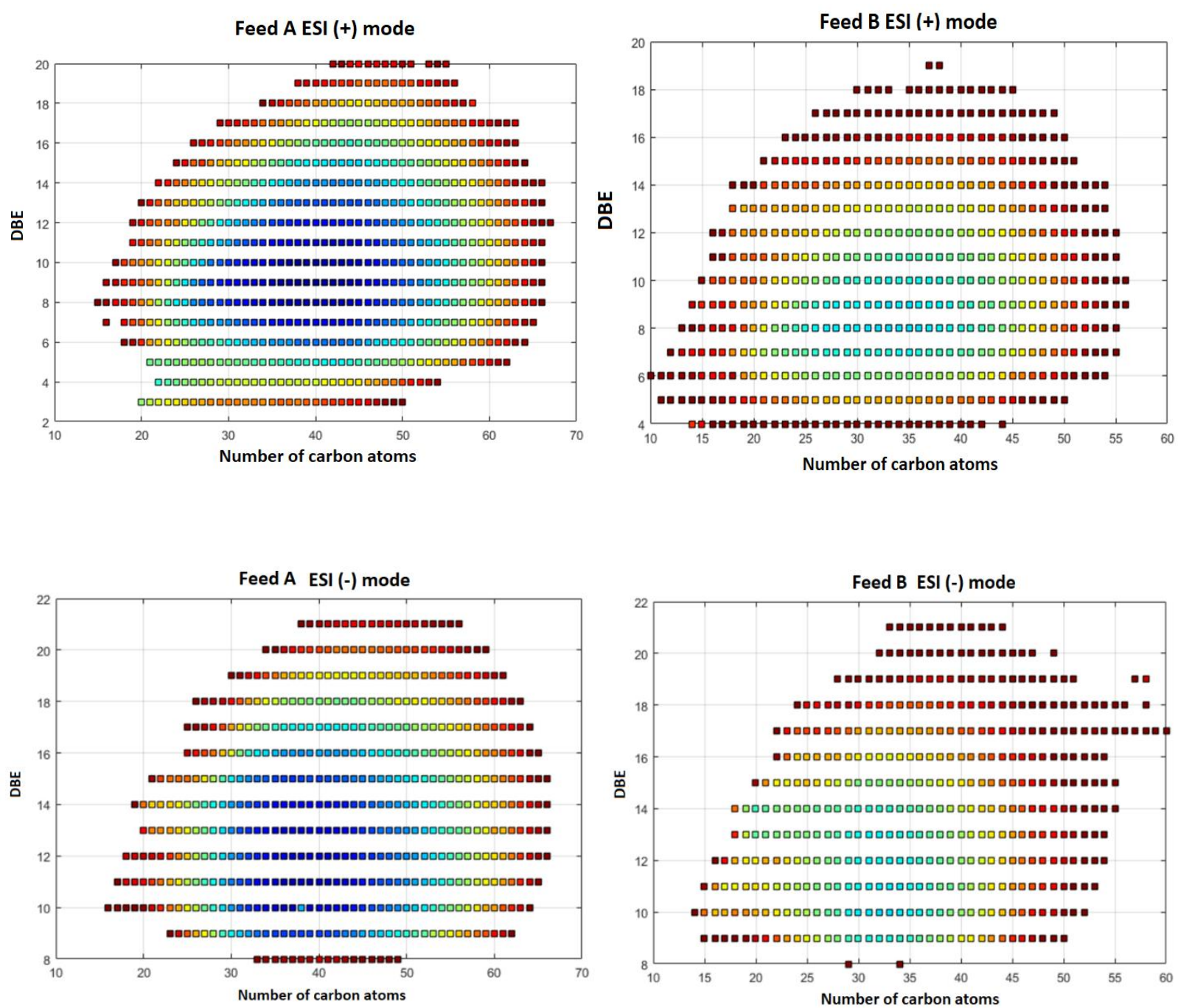

Both an exponential and a hyperbolic decay models were assumed to dissociate the deactivation from the kinetic performance. In these models, the catalyst deactivation (Y) depends on the deactivation constant (b) and time on stream (TOS). The experimental data of the evolution of cracking kinetic constant with time was then fitted to an exponential and a hyperbolic functions, the corresponding curves are shown below. 
Figure S 2. Exponential and hyperbolic decay models for test with feed A during 30 days
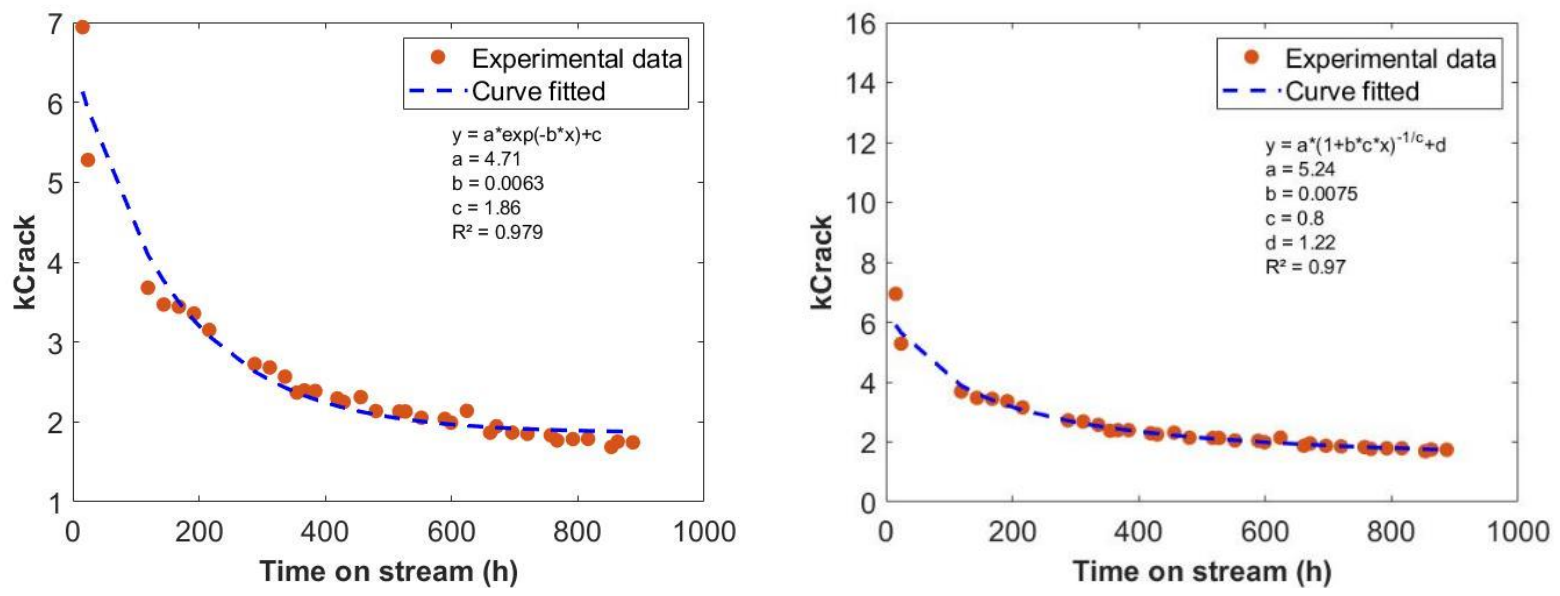

Exponential model

Hyperbolic model

Figure S 3. Exponential and hyperbolic decay models for test with feed B during 30 days
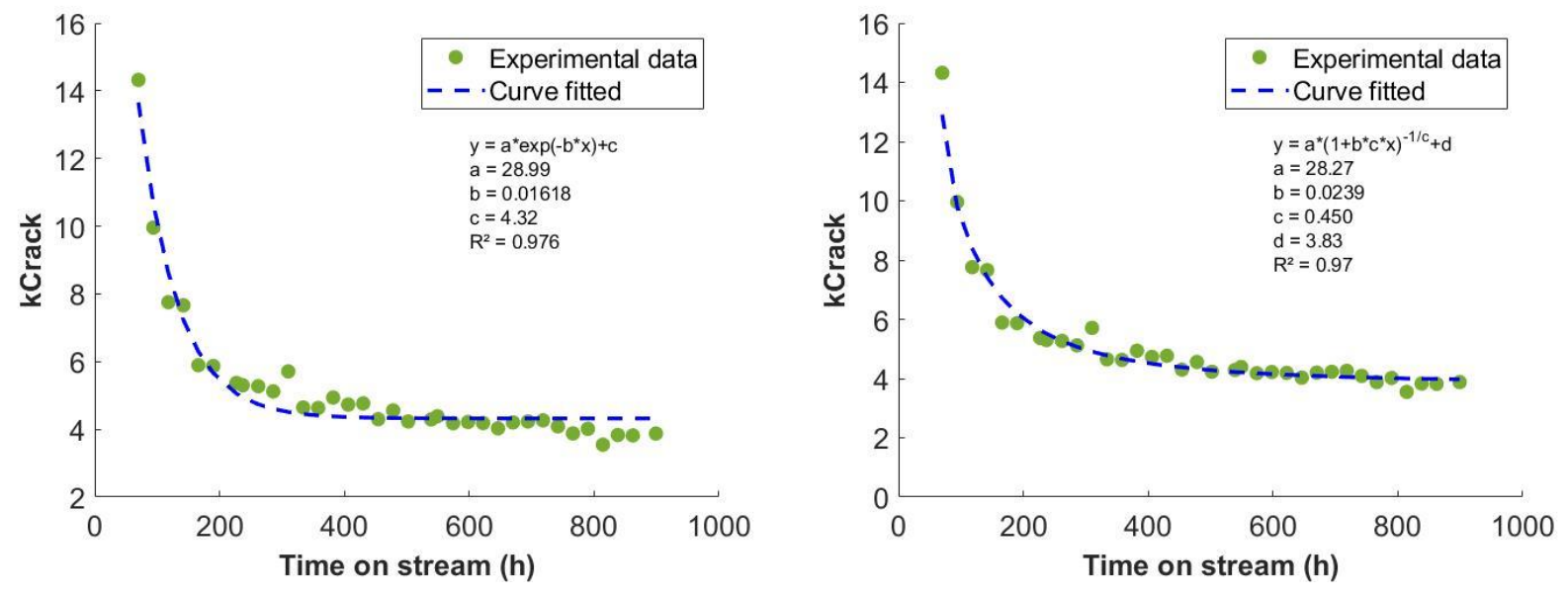

Exponential model

Hyperbolic model 
Figure S 4. Characterization of spent catalysts: loss of surface area (S) as function of carbon deposition. Circle $=6$ days tests, Diamond $=30$ days tests.

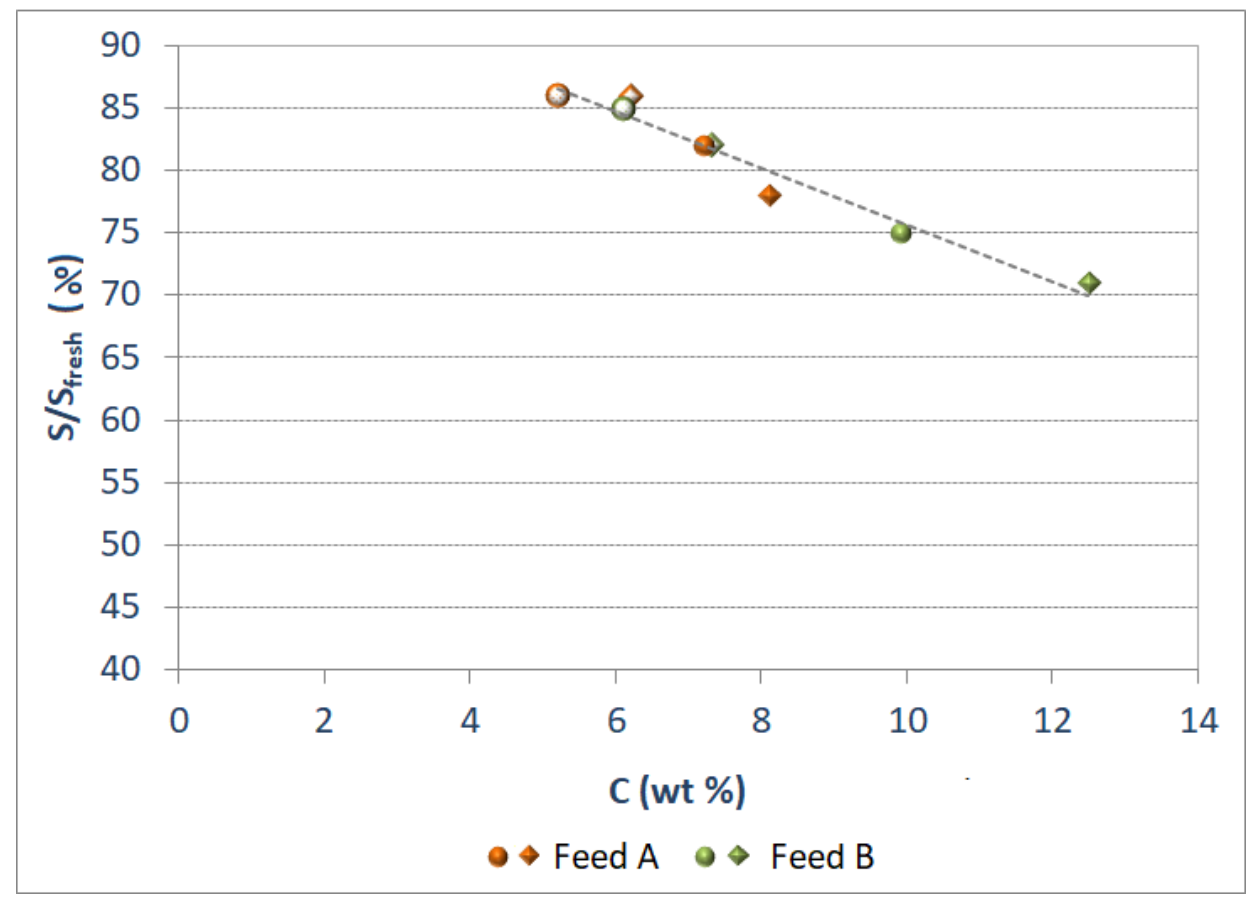

Figure S 5. Characterization of spent catalysts: loss of pore volume (V) as function of carbon deposition. Circle $=6$ days tests, Diamond $=30$ days tests.

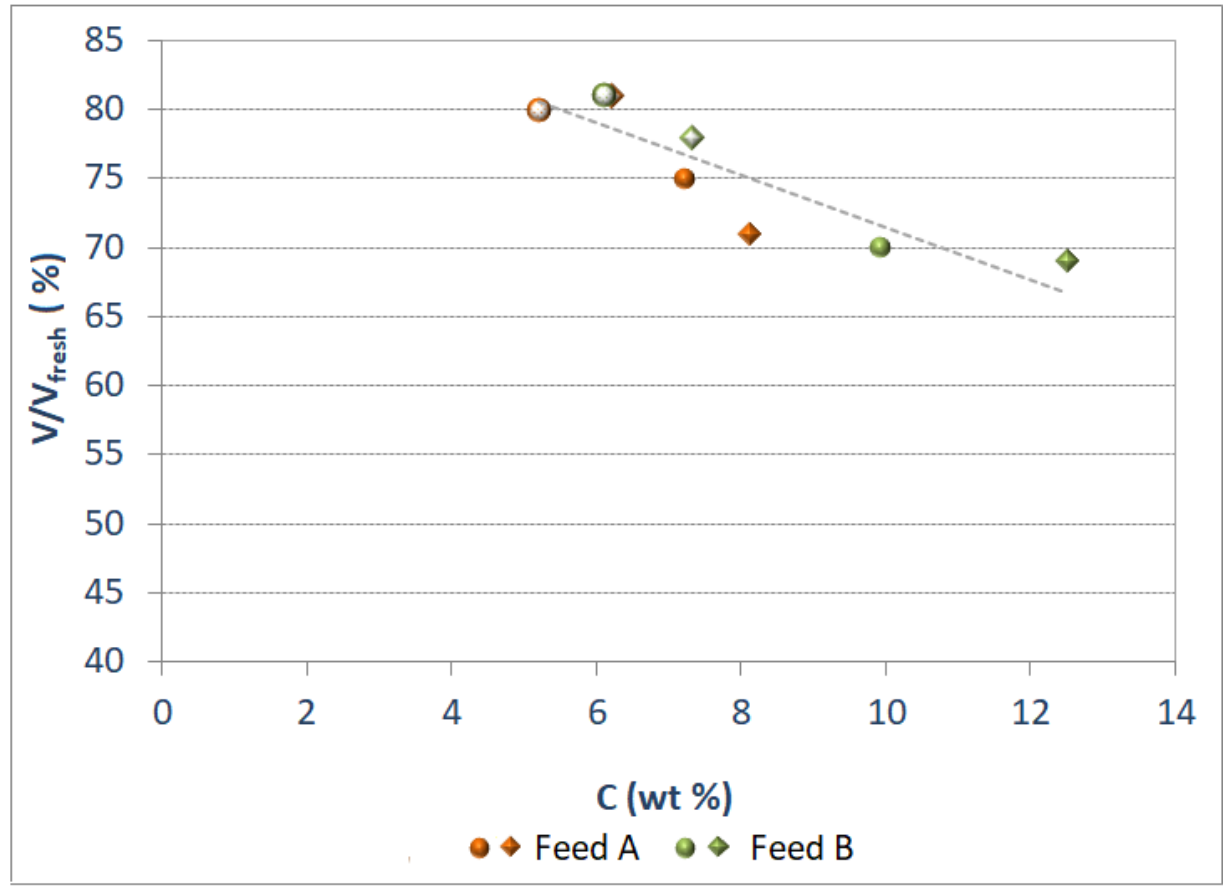




\section{S 6. Hydrogen consumption}

Table S 2points out the hydrogen consumption calculated from experimental data for the different feedstocks at the end of all the experiments. The results confirmed the higher reactivity of feed B compared to feed A. More cracking leads to a higher hydrogen consumption because each cracking event consumes one hydrogen molecule. The hydrogen consumption decreased over time which is proportional to the activity loss as time progress.

Table S 2. Hydrogen consumption and apparent cracking kinetic constant for both tests at different times.

\begin{tabular}{lcccc}
\hline Case & Time on stream & $\mathbf{H}_{\text {consumption }}^{\text {End of run }}$ & $\mathbf{k}_{\text {cracking }}^{\text {fresh callyst }}$ & $\mathbf{k}_{\text {cracking }}^{\text {spent catalyst }}$ \\
\hline & Days & $\mathrm{Nm}^{3} / \mathrm{m}^{3}$ & & \\
Feed A & 6 & 101 & $\sim 7$ & 2.3 \\
Feed A & 27 & 90 & $\sim 7$ & 1.7 \\
Feed B & 6 & 124 & $\sim 27$ & 4.5 \\
Feed B & 27 & 113 & $\sim 27$ & 3.8 \\
\hline
\end{tabular}

\section{S 7. Transmission electron microscopy (TEM) results}

Table S 2. Average stacking size and dispersion measured by TEM and Ni/Mo ratio in $\mathrm{MoS}_{2}$ particles measured by EDX.

\begin{tabular}{lcccc}
\hline & $\begin{array}{c}\text { Time on Stream } \\
\text { (days) }\end{array}$ & $\begin{array}{c}\text { Slab length } \\
\text { (nm) }\end{array}$ & Dispersion & Ni/Mo \\
\hline Feed A Bed In & 6 & $4.7 \pm 1.6$ & 0.20 & $0.24 \pm 0.08$ \\
Feed A Bed Out & 6 & $4.4 \pm 1.6$ & 0.22 & $0.21 \pm 0.12$ \\
Feed A Bed In & 30 & $4.3 \pm 1.7$ & 0.22 & $0.19 \pm 0.11$ \\
Feed A Bed Out & 30 & $4.6 \pm 2.2$ & 0.18 & $0.23 \pm 0.12$ \\
Feed B Bed In & 6 & $4.5 \pm 1.7$ & 0.20 & $0.19 \pm 0.06$ \\
Feed B Bed Out & 6 & $4.3 \pm 1.6$ & 0.21 & $0.20 \pm 0.07$ \\
Feed B Bed In & 30 & $4.6 \pm 1.5$ & 0.22 & $0.14 \pm 0.21$ \\
Feed B Bed Out & 30 & $4.6 \pm 1.7$ & 0.20 & $0.16 \pm 0.08$ \\
\hline
\end{tabular}

